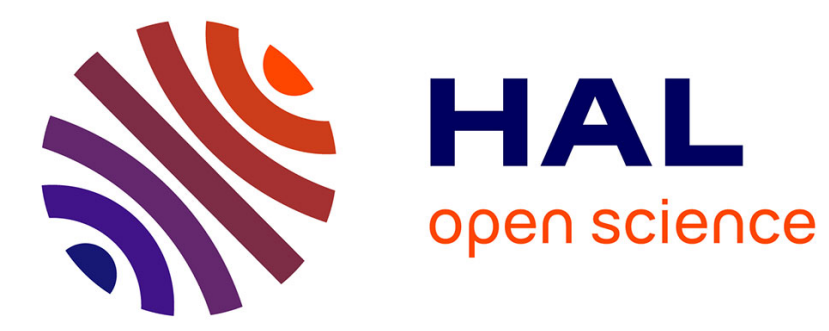

\title{
Computer Modelling for the Yield Strength of the Mixed Micro-Structures of Bainite and Martensite
}

\author{
C. Young, H. Bhadeshia
}

\section{To cite this version:}

C. Young, H. Bhadeshia. Computer Modelling for the Yield Strength of the Mixed Micro-Structures of Bainite and Martensite. Journal de Physique IV Proceedings, 1995, 05 (C8), pp.C8-267-C8-272. 10.1051/jp4:1995837 . jpa-00254086

\section{HAL Id: jpa-00254086 https://hal.science/jpa-00254086}

Submitted on 1 Jan 1995

HAL is a multi-disciplinary open access archive for the deposit and dissemination of scientific research documents, whether they are published or not. The documents may come from teaching and research institutions in France or abroad, or from public or private research centers.
L'archive ouverte pluridisciplinaire HAL, est destinée au dépôt et à la diffusion de documents scientifiques de niveau recherche, publiés ou non, émanant des établissements d'enseignement et de recherche français ou étrangers, des laboratoires publics ou privés. 


\title{
Computer Modelling for the Yield Strength of the Mixed Micro-Structures of Bainite and Martensite
}

\author{
C.H. Young and H.K.D.H. Bhadeshia* \\ National Taiwan Institute of Technology, Department of Construction Engineering, Taiwan, R.O.C. \\ * University of Cambridge/JRDC, Department of Materials Science and Metallurgy, Pembroke Street, \\ Cambridge CB2 $3 Q Z$, U.K.
}

\begin{abstract}
The strength of mixed microstructures of bainite and martensite can peak at an intermediate volume fraction of martensite has been published by recently experimental studies. A quantitative interpretation of these observations is achieved by modelling the mechanical properties of mixed microstructures of bainite and martensite. The peak in the curve of the strength as a function of the volume fraction of martensite can be attributed to two factors. It enriches the residual austenite with carbon when bainite forms, so that the strength of the subsequent martensite increases. In addition, the strength of the bainite is enhanced via plastic constraint by the surrounding stronger martensite. This means the bainite is under a tri-axial stress state. Taking these effects into consideration for the computer modelling, it is possible to predict accurately both the trends and the absolute values of published experimental data on the strength of mixed microstructures.
\end{abstract}

\section{INTRODUCTION}

Early indications ${ }^{1}$ that mixed microstructures of bainite and martensite can often outperform the individual phases have been strongly reinforced by the more recent work of Tomita and Okabayashi. ${ }^{2-7} \mathrm{~A}$ maximum is observed for the strength of a mixture of lower bainite and martensite in an isothermally transformed high strength steel (Table 1) as a function of the volume fraction of lower bainite (Fig. 1) Tomita and Okabayashi suggest that the peak in the strength can be explained by the effective refinement of the austenite by the bainite sheaves, which in turn refines the martensite that forms subsequently. This strengthens the martensite, and the bainite itself is considered to be strengthened owing to the constraint to its deformation by the stronger martensite.

The purpose of the present work is to account quantitatively for the strength of mixed microstructures of bainite and martensite, including restraint effects and changes in martensite composition (and hence strength) as bainite forms. ${ }^{8}$

Table 1 Chemical composition of high strength steel used by Okabayashi and Tomita $^{2}$,wt-\%

\begin{tabular}{ccccccc}
\hline $\mathrm{C}$ & $\mathrm{Si}$ & $\overline{\mathrm{Mn}}$ & $\overline{\mathrm{P}}$ & $\mathrm{Cr}$ & $\mathrm{Mo}$ & $\mathrm{Ni}$ \\
\hline 0.4 & 0.20 & 0.71 & 0.01 & 0.88 & 0.25 & 1.89 \\
\hline
\end{tabular}

\section{STRENGTH OF INDIVIDUAL PHASES}

The strength of martensite and bainite can be factorised into a number of intrinsic components ${ }^{8,9}$

$$
\sigma=\sigma_{\mathrm{Fe}}+\sum_{i} \sigma_{\mathrm{ss}, \mathrm{i}}+\sigma_{\mathrm{C}}+K_{\mathrm{L}}\left(\bar{L}_{3}\right)^{-1}+K_{D} \rho_{D}^{1 / 2}+K_{\mathrm{p}} \Delta^{-1}
$$

where $K_{L}, K_{D}$, and $K_{P}$ are constants, $\sigma_{\mathrm{Fe}}$ is the strength of pure annealed iron, $\sigma_{\mathrm{SS}, \mathrm{i}}$ is the solid solution strengthening due to substitutional solute $i, \sigma_{C}$ is the solid solution strengthening due to carbon, $\bar{L}_{3}$ is a measure of the ferrite plate size, $\rho_{D}$ is the dislocation density, and $\Delta$ is the distance between any carbide particles. The role of each of these components is now considered in detail. 


\subsection{Iron and substitutional solutes}

The method used to estimate the strength of untempered martensite and bainite is a development of an earlier technique for steel welds, ${ }^{9}$ where the strength is factorised into a number of components for which independent data are available in the literature.

Thus, pure bcc iron in a fully annealed condition makes an intrinsic contribution $\sigma_{\mathrm{Fe}}{ }^{10-12}$ Substitutional solutes do not partition during the growth of either martensite or bainite, so their concentrations are fixed by the composition of the steel as a whole. Solid solution strengthening contributions $\sigma_{\mathrm{ss}, \mathrm{i}}$ can be estimated as a function of temperature and strain rate from published data. ${ }^{9,13-19}$

\subsection{Carbon}

Bainitic ferrite has only a small amount of carbon dissolved in interstitial solution, assumed to be 0.03 wt$\%$. Martensite on the other hand can have carbon concentrations well in excess of the average carbon concentration of the alloy $\bar{x}$, since the prior formation of bainite enriches the residual austenite according to the following relationship derived from mass balance considerations

$$
x_{y}=\frac{\bar{x}-V_{\mathrm{b}} x_{\mathrm{b}}}{1-V_{\mathrm{b}}}
$$

where $x_{y}$ is the carbon concentration in the residual austenite before its transformation to martensite, $\mathrm{V}_{\mathrm{b}}$ is the volume fraction of bainitic ferrite, and $x_{b}$ is the carbon that remains in the bainitic ferrite.

There is theoretical justification for assuming that the strength increment due to dissolved carbon should vary with the square root of the carbon concentration. ${ }^{20}$ Data from Speich and Warlimont ${ }^{21}$ are consistent with this

$$
\sigma_{s, c}=1722.5 x^{12}
$$

where strength is in $\mathrm{MN} \mathrm{m} \mathrm{m}^{-2}$ and the concentration is in wt-\%. This equation is used here to represent bainitic ferrite, but the data do not extend to the much larger concentrations appropriate for the martensite in the mixed microstructures. Thus, an earlier equation due to Winchell and Cohen ${ }^{22}$ is used instead for martensite

$$
\sigma_{\mathrm{ss}, \mathrm{c}}=1171.3 x^{\mathrm{r} 3}
$$

with units as above. This avoids an overestimation of the strength of the martensite at high carbon concentrations, consistent with the experimental data of Winchell and Cohen.

\subsection{Dislocations}

When the transformation occurs at a temperature where the shape change cannot be accommodated elastically, the plastic deformation that is driven by the shape change causes the accumulation of dislocations in both the parent and product phases. Both the tendency for plastic accommodation and any recovery effects should depend largely on the transformation temperature. Therefore, it is not surprising that the dislocation density $\rho_{D}$ of both martensite and bainite can be represented empirically as a function of temperature alone ${ }^{23}$

$$
\log \left\{\rho_{\mathrm{D}}\right\}=9.2840+\frac{6880.73}{\mathrm{~T}}-\frac{1780360}{\mathrm{~T}^{2}}
$$

where $T$ is the transformation temperature in kelvin and $\rho_{D}$ is stated in units of $\mathrm{m}^{-2}$. The equation is based on experimental data over the temperature range $570-920 \mathrm{~K}$. Although this covers most low alloy steels, in the present context the carbon concentration of the austenite that remains after partial transformation to bainite can be very high. Therefore, it is necessary in some cases to know the dislocation density of martensite which forms at temperatures below 570K. The above equation cannot be extrapolated because of its empirical basis, but it is reasonable to assume that the dislocation density does not continue to increase indefinitely as the transformation temperature decreases. Instead, it should stabilise at some limiting value, since any reduction in dislocation density caused by dynamic recovery effects must become negligible at low temperatures. Thus, it is assumed here that $\rho_{\mathrm{D}}$ for $\mathrm{T}<520 \mathrm{~K}$ is given by the value at $520 \mathrm{~K}$ (Fig.2). The strengthening $\sigma_{p}\left(\mathrm{MN} \mathrm{m}^{-2}\right)$ due to dislocations can be estimated to be $\mathrm{e}^{24}$ 


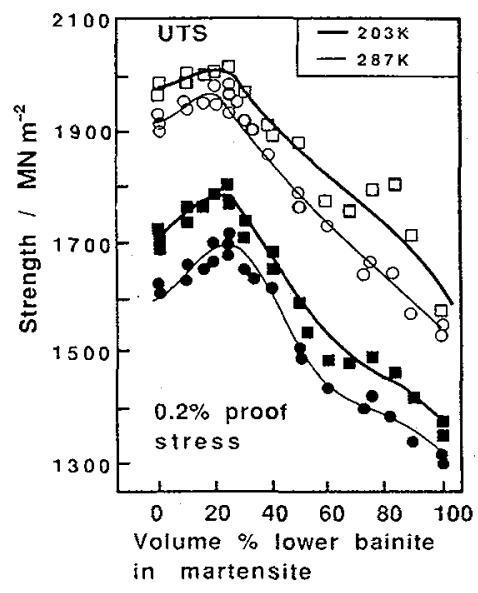

Figure 1: Variation in $0.2 \%$ proof stress as function of volume fraction of lower bainite in mixed, tempered microstructure of lower bainite and martensite of isothermally transformed high strength steel: ${ }^{2}$ curves respresent data collected at temperatures indicated on diagram

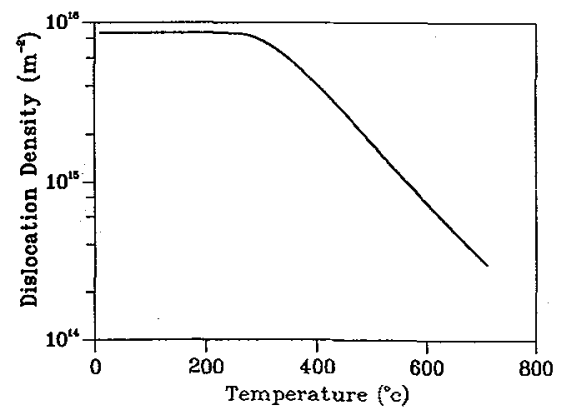

Figure 2: Assumed variation in dislocation density of martensite or of bainite as function of transformation start temperature

$$
\sigma_{\rho}=0.38 \mu b \rho_{D}^{1 / 2} \approx 7.34 \times 10^{-6} \rho_{D}^{1 / 2}
$$

where $\mu$ is the shear modulus and $b$ is the magnitude of the Burgers vector.

\subsection{Lath size}

The three-dimensional shape of martensite and bainite in low alloy steels is that of very fine plates or laths. However, in high strength steels of the type considered here, the shape is best described in terms of a plate morphology since isotropic sections are seldom observed. The strengthening $\sigma_{\mathrm{G}}$ due to the fine lath size then depends inversely on the mean value of the larger diameter of slip planes. ${ }^{25.26}$

The thickness $t$ is in turn given approximately by ${ }^{8} \bar{L}_{3}=2 t$, where $\bar{L}_{3}$ is a mean lineal intercept measured at random orientations on random sections. It is assumed here that these represent approximately $\bar{L}_{3}(\mu \mathrm{m})$. Thus, the strengthening due to the grain size of the plates $\sigma_{\mathrm{G}}\left(\mathrm{MN} \mathrm{m}^{-2}\right)$, for both martensite and bainite, is given by ${ }^{8,25.26}$

$$
\sigma_{G} \approx 115\left(\bar{L}_{3}\right)^{-1}
$$

\subsection{Cementite particles}

The strengthening $\sigma_{\theta}\left(\mathrm{MN} \mathrm{m}^{-2}\right)$ due to a uniform dispersal of spherical cementite particles is given by

$$
\sigma_{\theta} \approx 0.52 V_{\theta} \Delta^{-1}
$$

where $\Delta$ is the particle spacing and $V_{\theta}$ is the volume fraction of the cementite [8].

In the present work it is assumed that cementite precipitation does not make a significant contribution to the strength, but that the carbon that is rejected into the austenite makes an important contribution via its effect on the solid solution strengthening of any martensite that subsequently forms as the austenite cools to ambient temperature or due to subzero treatment (as in the work of Tomita and Okabayashi).

\section{MARTENSITE COMPOSITION AND TRANSFORMATION TEMPERATURE}

Given that the excess carbon in the bainitic ferrite partitions into the residual austenite, which then transforms to martensite, it is possible to estimate the carbon concentration according to the mass balance 
condition stated above (equation (2)). Following Steven and Haynes, ${ }^{27}$ the martensite start temperature $M_{s}$ of the residual austenite can be written as

$$
M_{\mathrm{s}}=M_{\mathrm{s}}^{\circ}-564\left(x_{y}-\bar{x}\right)
$$

where the concentrations are in wt- $\%$, the temperatures in ${ }^{\circ} \mathrm{C}$, and $M_{s}^{\circ}$ is the martensite start temperature of the austenite that has the average composition of the alloy. The $M_{\mathrm{s}}^{\circ}$ temperature can be calculated using either the Steven and Haynes ${ }^{27}$ equation or other methods. ${ }^{2830}$ Estimation of the martensite start temperature is important because it determines the dislocation density.

\section{EFFECT OF TEMPERING}

The microstructures developed by Tomita and Okabayashi were tempered for $2 \mathrm{~h}$ at $473 \mathrm{~K}\left(M_{\mathrm{s}}^{\circ}=586 \mathrm{~K}\right)$. However, the same approximation is not valid for martensite which in the mixed microstructure is expected to contain a large concentration of carbon. The effect of tempering can be estimated using a recent model by Takahashi and Bhadeshia. ${ }^{23}$ Assuming that hardness is linearly related to strength, that of tempered martensite $\sigma_{\mathrm{MT}}$ is given by

$$
\sigma_{\mathrm{MT}}=\sigma_{\mathrm{M}}-\xi\{t\}\left(\sigma_{\mathrm{M}}-\sigma_{\mathrm{B}}\right)
$$

where $\sigma_{\mathrm{M}}$ is the strength of virgin martensite and $\sigma_{\mathrm{B}}$ that of martensite without any excess carbon (in the present case, equivalent to the strength of bainite). The Avrami function $\xi$ is

$$
\xi=1-\exp \left\{-k t^{\mathbf{n}}\right\}
$$

with $\mathrm{n}=0.62$ (Ref. 23 ), $\mathrm{t}$ is the tempering time (h), and $\mathrm{k}$ is given by

$$
k=k_{0} \exp \{-Q / R T\}
$$

where $k_{0}=4.07 \times 10^{4} \bar{X}^{0.635}$ ( $\bar{X}$ is the atom fraction of carbon and the unit of $k_{0}$ is $\left.h^{-0.62}\right), Q=33598 \mathrm{~J} \mathrm{~mol}^{-1}$ $R$ is the gas constant, and $T$ is the absolute temperature.

\section{STRENGTH OF MIXED MICROSTRUCTURE}

It is well established in fracture mechanics that the yield strength is increased by plastic constraint. Hence, a weak brazing alloy can be used effectively to bond much stronger specimens provided that the thickness of the braze material is small enough to be constrained throughout by the surrounding stronger matrix. Indeed, the strength of the joint increases as the thickness of the braze layer decreases. ${ }^{31}$

Dispersions of bainite plates form in austenite which subsequently transforms to much stronger martensite. This is similar to a brazed joint in which the strong base material is connected to the soft braze. The deformation of the bainitic ferrite can therefore be expected to be constrained by the martensite. The effect can be modelled approximately by using experimental data ${ }^{31-34}$ available from brazed joints in high strength steels. The brazing alloys used in making the joints were non-ferrous materials which are ordinarily rather weak. The data, in a normalised form, are summarised in Fig.3. The strength is normalised with respect to the tensile strength of the pure unconstrained braze material, whereas the thickness is normalised relative to a value where the restraint effect vanishes.

The application of these data to the problem of a mixed microstructure of bainite and martensite relies on the assumption that the normalised thickness is equivalent to the volume fraction of bainite. This approximation should be taken as valid only at small volume fractions of bainite, but there are no difficulties at larger fractions since the constraint effect is expected to diminish rapidly as the volume fraction of bainite increases. Using this assumption, and the form of the normalised strength versus normalised thickness plot, the strength of constrained bainite may be represented by the equation.

$$
\sigma_{\mathrm{B}} \approx \sigma_{\mathrm{B}}\left(0.65 \exp \left\{-3.3 V_{b}\right\}+0.98\right) \leq \sigma_{\mathrm{M}}
$$

where $\sigma_{\mathrm{B}}$ and $\sigma_{\mathrm{B}}^{\prime}$ represent the strengths of constrained and unconstrained bainite respectively, $\sigma_{\mathrm{M}}$ is the strength of martensite, and $V_{\mathrm{b}}$ is the volume fraction of bainitic ferrite. Note that the strength of bainite is always restricted to be less than or equal to that of martensite. The above equation was used in the calculations to represent the strength of constrained bainite.

The strength of martensite continues to increase with the fraction of bainite, as the carbon concentration of the residual austenite from which it forms increases. This is an approximation; the very constraint which strengthens the bainite must make the martensite yield at a lower strength compared with a fully martensitic sample of the same composition. ${ }^{35}$ 


\section{RESULTS AND DISCUSSION}

Tomita and Okabayashi have accumulated considerable data on the strength of mixed microstructures of bainite and martensite; all their data have been compared against the above model. Figure 4a shows that the strengths of completely or partly martensitic specimens are accurately predicted, this being a general feature of the model as will be seen from further data presented below. Line A on Fig. 4a shows that a rule of mixtures cannot fully account for the variations observed. The agreement between calculation and experiment improves (curve B) as allowance is made for the change in the strength of martensite as carbon partitions into the austenite due to the formation of bainite. The consistency between experiment and theory becomes excellent when constraint effects are also included in the calculations (curve $C$ ).

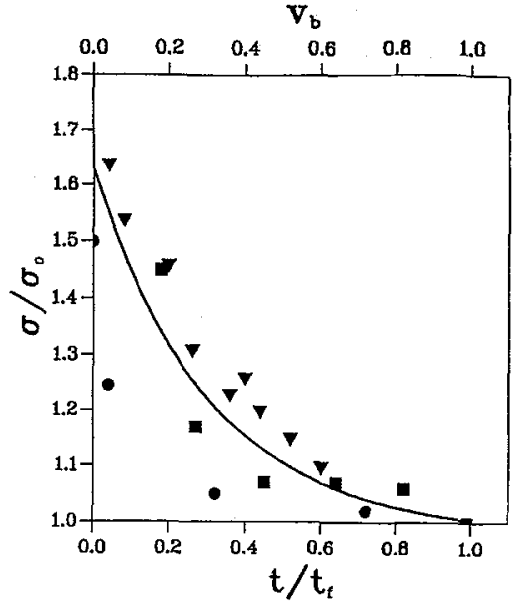

Figure 3: Plot of normalised strength of brazed joint versus normalised thickness of brazing material: data taken from Refs. ${ }^{32-34}$

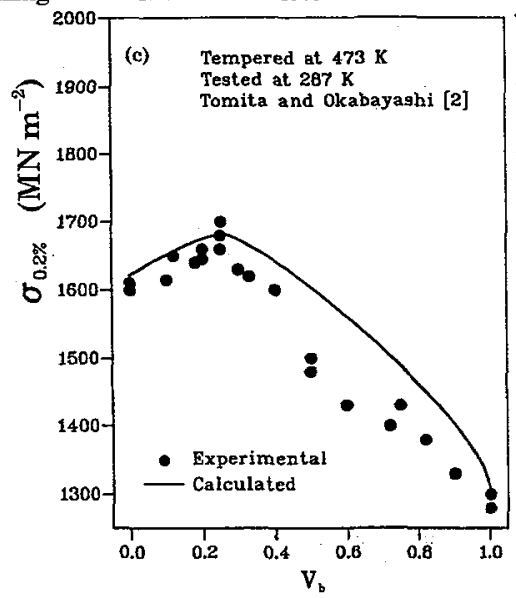

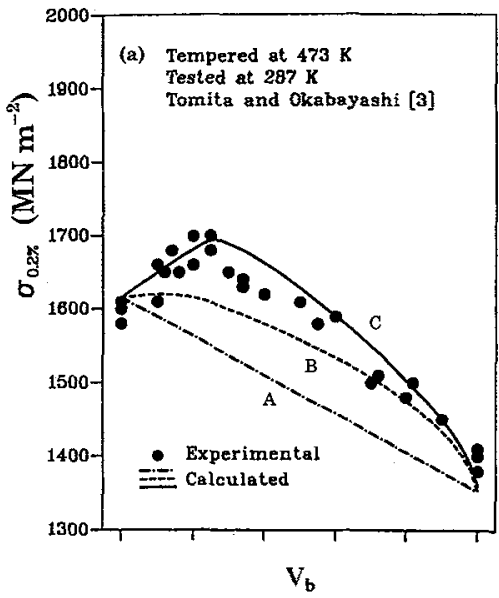

(b) Tempered at 470 Tested at $203 \mathrm{~K}$ Tomita and Okabayaghi [3]

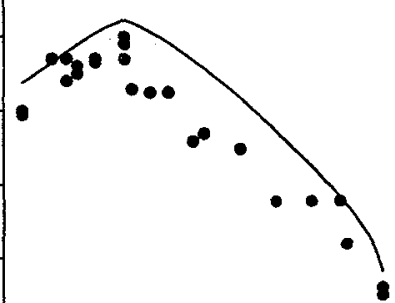

Figure 4: Comparison between experimental data ${ }^{2,3}$ and theory
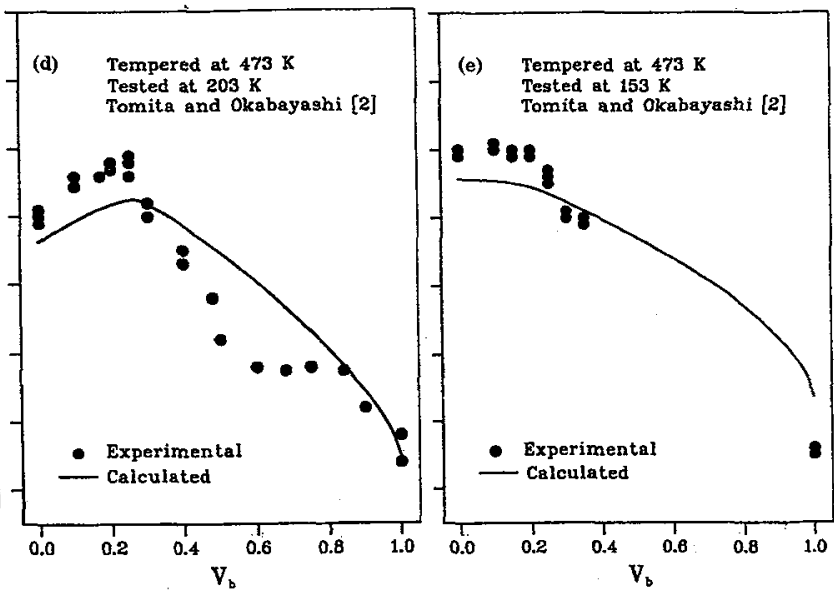

Figure 4: Comparison between experimental data ${ }^{2,3}$ and theory

Similar analyses are illustrated in Figs. 4b-4d, covering different steels and various test temperatures. The predictions of strength appear to deteriorate slightly as the test temperature is reduced (Figs. 4b, 4d). The variations in the strength of iron and the solid solution strengthening effects are included in the calculations; however, the temperature dependence of carbon, grain size, and dislocation strengthening are not considered owing to lack of appropriate data. Whether this accounts for the discrepancies is not clear because the detailed discrepancies do not appear to be systematic.

It is of interest that for the lowest temperature tests (Fig. 4e), neither experiment nor theory exhibits any significant peak in strength as a function of the volume fraction of bainite. The reason for this is that the strength of iron increases considerably as the temperature decreases, which means that the difference 
between the strength of martensite and bainite decreases, so that any constraint effect becomes less important.

\section{CONCLUSIONS}

It seems that the peak in the strength of mixed microstructures of bainite and martensite can be explained on the basis of two factors.

(1) The first is the increase in the strength of martensite as carbon is partitioned into the residual austenite during the formation of bainite. However, this does not fully account for experimental data.

(2) It is necessary to include a plastic constraint effect in which the strength of bainite is enhanced, particularly at low volume fractions of bainite, by the surrounding relatively rigid martensite.

The computer modelling of the relations of macro-mechanical properties and mixed micro-structures of martensite and bainite fairly describes the experimental results.

\section{References}

[1] EDWARDS.D.P.: J. Iron Steel Inst., (1969), 207 , 1494-1502.

[2] TOMITA Y. and OKABAYASHI K.: Metall. Trans., (1983), 14A, 485 - 492.

[3] TOMITA Y. and OKABAYASHI K.: Metall. Trans., (1983), 14A, 2387 - 2393.

[4] TOMITA Y. and OKABAYASHI K.: Metall. Trans., (1985), 16A, 73-82.

[5] TOMITA Y. and OKABAYASHI K.: Metall. Trans., (1985), 16A, 83-91.

[6] TOMITA Y.: Metall. Trans., (1987), 18A, 1495-1501.

[7] TOMITA Y.: Metall. Trans., (1987), 18A, 2513-2521.

[8] BHADESHIA H.K.D.H.: 'Bainite in steels'; (1992), London, The Institute of Materials.

[9] SUGDEN A.A.B. and BHADESHIA H.K.D.H.: Metall. Trans.,(1988), 19A, 1597-1602.

[10] CONRAD H. and FREDRICK S.: Acta Metall., (1962), 10, 1013-1020.

[11] ALTSHULER T.L. and CHRISTIAN J.W.: Proc. R. Soc., (1967), 261A, 253-287.

[12] KIMURA H., MATSUI H., TAKAKI S., KIMURA A., and OGURI K.: in Proc. Conf. on 'Mechanical properties of bec metals', (ed.M. Meshii), 125-133; (1981), Warrendale,PA, The Metallurgical Society of AIME

[13] LESLIE W.C.: Metall. Trans., (1972), 3, 5-26.

[14] KITAJIMA K., AONA Y., ABE H., and KURAMOTO E.: in Proc. Conf. on 'Strength of metals and alloys', (ed. P. Haasen), Vol. 2, 965-970; (1979), Oxford, Pergamon Press.

[15] TAKEUCHI S.: J. Phys. Soc. Jpn, (1969), 27, 167-169.

[16] TAKEUCHI S., YOSHIDA H., and TAOKA T.: Trans. Jpn Inst. Metals, (1968), 9, 715-719 (conf. suppl.).

[17] IRVINE K.J. and PICKERING F.B.: J. Iron Steel Inst., (1963), 201, 518-531.

[18] CHILTON J.M. and KELLY P.M.: Acta Metall., (1968), 16, 637-656.

[19] NORSTROM L.-A.: Scand. J. Metall., (1976), 5, 159-165.

[20] CHRISTIAN J.W.: 'Strengthening methods in crystals', (ed. A. Kelly and R. Nicholson), 261-329; (1971), Amsterdam, Elsevier/North Holland.

[21] SPEICH G.R. and WARLIMONT H.: J. Iron Steel Inst., (1968), 206, 385-392.

[22] WINCHELL P.G. and COHEN M.: Trans. ASM, (1962), 55, 347-361.

[23] TAKAHASHI M. AND BHADESHIA H.K.D.H.: Mater. Sci. Technol., (1990), 6, 592-603.

[24] KEH A.S. and WEISSMANN S.: 'Electron microscopy and the strength of crystals', (ed. G. Thomas and J. Washburn), 231-300; (1963), New York, Interscience.

[25] NAYLOR J.P.: Metall. Trans., (1979), 10A, 861.

[26] DAIGNE J., GUTTMANN N., and NAYLOR J.P.: Mater.Sci. Eng., (1982), 56, 1-10.

[27] STEVEN W. and HAYNES A.G.: J. Iron Steel Inst., (1956), 183, 349-359.

[28] KUNG C.Y. and RAYMENT J.J.: Metall. Trans., (1982), 13A, 328-331.

[29] BHADESHIA H.K.D.H.: Met. Sci., (1981), 15, 175-177.

[30] BHADESHIA H.K.D.H.: Met. Sci., (1981), 15, 178-180.

[31] BREDZS N.: Weld. J. (suppl.), November (1954), 545s-563s.

[32] CASE S.L.: Steel Process., (1950), (5), 238-243.

[33] CASE S.L.: 'Monograph on brazing of steel', US Army Air Forces Technical Report 5602, (1947) (quoted in Ref. 31).

[34] HANDY and HARMAN: Technical Bulletin No. T3, (1951) (quoted in Ref. 31).

[35] TOMOTA Y., KUROKI K., MORI T., and TAMURA I.: Mater. Sci. Eng., (1976), 24, 41-49.

[36] BHADESHIA H. K. D. H.and EDMONDS D.V: Met. Sci., (1983), 17, 411-419. 